\title{
Soy Protein Isolate Suppresses Lipodystrophy- induced Hepatic Lipid Accumulation in Model Mice
}

\author{
Koji Nagao $^{1 *}$, Akiko Matsumoto ${ }^{1}$, Shunichi Kai ${ }^{1}$, Tomoko Kayashima ${ }^{2}$ and \\ Teruyoshi Yanagita ${ }^{1,3}$ \\ ${ }^{1}$ Department of Applied Biochemistry and Food Science, Saga University, Saga 840-8502, JAPAN \\ ${ }^{2}$ Faculty of Culture and Education, Saga University, 1 Honjo-machi, Saga-shi, Saga 840-8502, JAPAN \\ ${ }^{3}$ Department of Health and Nutrition Sciences, Nishikyushu University, Kanzaki 842-8585, JAPAN
}

\begin{abstract}
Lipodystrophies are acquired and genetic disorders characterized by the complete or partial absence of body fat with a line of metabolic disorders, including hepatic steatosis. Because soy protein isolate (SPI) has been reported to reduce cholesterol and triglyceride levels in animals and humans, we explored the effect of SPI on the pathophysiology of hepatic lipid accumutaion in a diet-induced lipodystrophy model mice. Four weeks of the lipodystrophy model diet induced hepatic lipid accumulation concomitant with marked deficiencies of adipose tissue and serum adipocytokines in mice. However, supplementing the lipodystrophy model diet with SPI could alleviate the hepatic lipid acculation without affecting the lipoatrophic effect of the diet. Enhanced lipogenesis is the principal mechanism of hepatic steatosis in this model, but SPI supplementation significantly attenuated the increase in enzyme activity and/or mRNA expression. Additionally, SPI supplementation upregulated the hepatic mRNA expression of an enzyme involved in cholesterol catabolism. In conclusion, our results indicate the possibility of dietary SPI to attenuate lipodystorophy-induced hepatic steatosis through the direct reduction of hepatic lipogenesis without affecting adipocytokine production.
\end{abstract}

Key words: hepatic steatosis, lipodystrophy, soy protein isolate, lipogenic enzymes

\section{Introduction}

Adipose tissue not only stores excess energy in the form of fat but also secretes physiologically active substances called adipocytokines ${ }^{1)}$. In obesity, adipocytes are increased and enlarged, and they secrete excess amounts of inflammatory adipocytokines, such as tumor necrosis factor-al$\mathrm{pha}^{2)}$ and monocyte chemoattractant protein- ${ }^{3)}$. This induces insulin resistance, hyperinsulinemia, and hepatic steatosis $^{4,5)}$. However, adipocyte deficiency also induces type 2 diabetes due to a paucity of normally functioning adipocytokines, such as leptin ${ }^{6)}$ and adiponectin ${ }^{7,8)}$. This symptom is known as lipodystrophy in humans. Lipodystrophies are acquired and genetic disorders characterized by the complete or partial absence of body fat with a line of metabolic disorders ${ }^{9}{ }^{10)}$. Recently, the acquired lipodystrophy that occurs in HIV-infected patients receiving highly active antiretroviral therapy (HAART) has become common ${ }^{10)}$.

To understand the metabolic complications in lipodystrophy and to evaluate the efficacy and safety of clinical treatments, several transgenic mouse models that mimic the features of lipodystrophy, such as aP2-SREBP-1c mice $^{11,12)}$ and A-ZIP/F1 mice ${ }^{13,14)}$, have been established. Additionally, it has been reported that feeding of conjugated linoleic acid (CLA), a group of positional and geometric isomers of linoleic acid, with a low-fat diet also induces lipodystrophy, characterized by an increase in hepatic lipid content concomitant with a decrease in body fat mass in mice ${ }^{15-19)}$. Because CLA induces metabolic abnormalities through the drastic reduction of adipocytokine levels due

Abbreviations: ACAT, acyl-coenzyme A:cholesterol acyltransferase; ACC, acetyl-coenzyme A carboxylase; CLA, conjugated linoleic acid; CPT, carnitine palmitoyltransferase; CYP7A1, cholesterol $7 \alpha$-hydroxylase; G6PDH, glucose 6-phosphate dehydrogenase; FAS, fatty acid synthase; HAAT, highly active antiretroviral therapy; HALS, HIV-associated lipodystrophy syndrome; HMG-CoA, 3-hydroxy-3-methylglutaryl-coenzyme A; ME, malic enzyme; SPI, soy protein isolate; SREBP, sterol regulatory element binding protein; WAT, white adipose tissue.

\footnotetext{
*Correspondence to: Koji Nagao, Department of Applied Biochemistry and Food Science, Saga University, Saga 840-8502, JAPAN

E-mail: knagao@cc.saga-u.ac.jp

Accepted September 2, 2016 (received for review July 22, 2016)

Journal of Oleo Science ISSN 1345-8957 print / ISSN 1347-3352 online

http://www.jstage.jst.go.jp/browse/jos/ http://mc.manusriptcentral.com/jjocs
} 


\section{K. Nagao, A. Matsumoto and S. Kai et al.}

to a paucity of adipose tissue, but not through the direct induction of hepatic lipid synthesis and insulin resistance, previous reports suggested the possibility of CLA-fed mice as a diet-induced lipodystrophy model ${ }^{15-19)}$.

It has been reported that leptin treatment attenuates metabolic abnormalities in lipodystrophy model transgenic mice (such as aP2-SREBP-1c mice) ${ }^{20)}$ and in patients with many types of lipodystrophy, including HIV-associated lipodystrophy syndrome (HALS) ${ }^{21,22)}$. In good agreement with those previous results, leptin infusion lowered the serum insulin level and attenuated the hepatic steatosis in the diet-induced lipodystrophy model mice ${ }^{19)}$. Additionally, treatment with antidiabetic agents (such as metformin and thiazolidinediones) and/or lipid-lowering agents (such as statins and fibrates) has been shown to attenuate diabetes mellitus or dyslipidemia in patients with HALS ${ }^{10)}$. However, possible adverse effects of those medications and drugdrug interactions should be carefully considered in patients with HAART.

Although leptin treatment and drug therapy are useful, a dietary therapy that is a cost-effective and a non-toxic intervention would also be helpful in managing metabolic abnormalities in patients with lipodystrophy. Previous reports demonstrated that dietary $\omega 3$ fatty acid supplementation reduces triglyceride levels in patients with $\operatorname{HALS}^{23,24)}$ and dietary docosahexaenoic acid (22:6 $\omega 3$, DHA) alleviates hepatic steatosis in the diet-induced lipodystrophy model mice $^{25)}$. Additionally, it has also been suggested that dietary treatment with fiber, vitamin $\mathrm{E}$, and medium-chain fatty acids may benefit patients with HALS ${ }^{10)}$.

In general, plant protein intake is inversely related to the risk of metabolic abnormalities, such as non-alcoholic fatty liver disease and cardiovascular disease ${ }^{26,27)}$. For example, several studies have shown that dietary soy protein isolate (SPI) reduces cholesterol and triglyceride levels in animals and humans ${ }^{26-29)}$. Because the effect of dietary SPI on lipodystrophy -induced metabolic abnormalities have not been evaluated, in this study, we evaluate the physiological function of SPI in the diet-induced lipodystrophy model mice.

\section{Materials and methods}

\subsection{Animals and diets}

Male C57BL/6J mice aged 8 wk were purchased from Japan Clea (Osaka, Japan) and housed individually in an airconditioned room $\left(24^{\circ} \mathrm{C}\right)$ with a 12 -h light/dark cycle. After a 1-wk adaptation period, the mice were assigned to three groups (five mice each). The basal diets were prepared according to recommendations of the AIN-93G ${ }^{30)}$. Dietary protein and fats were composed of $20 \%$ casein and a mixture of $4 \%$ corn oil $+2 \%$ high linoleic safflower oil (HL-SAF) in the normal diet, $20 \%$ casein and a mixture of $4 \%$ corn oil $+2 \%$ CLA in the lipodystrophy-control diet, and $20.5 \%$ SPI and a mixture of $4 \%$ corn oil $+2 \%$ CLA in the lipodystrophy-SPI diet. The compositions of the semisynthetic diets and their fatty acid contents are given in Table 1. The mice received the diets ad libitum using Roden CAFE (KBT Oriental Co. Ltd., Saga, Japan) for 4 wk. The mice were killed by exsanguination of the heart after 9 $\mathrm{h}$ starvation, and serum was separated from the blood. The liver and WATs (epididymal and perirenal)were also excised for analysis. All aspects of the experiment were conducted according to the guidelines provided by the Ethical Committee of Experimental Animal Care at Saga University. The authorization number of the experiment was 19-002-1.

\subsection{Histopathological study of the liver}

A piece of liver was immediately fixed in $10 \%$ buffered formalin for histological examination. Formalin-fixed liver tissues were embedded in paraffin and sectioned into 4 micrometer thicknesses. Liver tissue sections were stained by hematoxylin and eosin to microscopically evaluate the degree of hepatic steatosis.

\subsection{Analysis of hepatic lipids and serum parameters}

Liver lipids were extracted according to the method of Folch et $a l{ }^{31)}$, and the concentrations of triglyceride and cholesterol were measured using the methods of Fletch$\mathrm{er}^{32)}$ and Sperry and $\mathrm{Webb}^{33)}$, respectively. The triglyceride, cholesterol, and glucose levels in the serum and the hepatic free cholesterol level were measured using enzyme assay kits from Wako Pure Chemicals (Tokyo, Japan). Serum insulin, adiponectin and leptin levels were measured using commercial mouse ELISA kits (Shibayagi Co. Ltd., Gunma, Japan; Otsuka Pharmaceutical Co. Ltd., Tokyo; and Morinaga Co. Ltd., Yokohama, respectively).

\subsection{Measurement of hepatic enzyme activities}

A piece of liver was homogenized in six volumes of a $0.25-\mathrm{M}$ sucrose solution that contained $1 \mathrm{mM}$ EDTA in a 10-mM Tris-HCl buffer ( $\mathrm{pH}$ 7.4). Fractions of cytosol and microsomes were obtained as previously described ${ }^{34)}$. The protein concentration was determined according to the method of Lowry et $a l^{35)}$, with bovine serum albumin used as the standard. The enzyme activities of fatty acid synthase (FAS), glucose 6-phosphate dehydrogenase (G6PDH), malic enzyme (ME), and carnitine palmitoyltransferase (CPT) were determined as previously described $^{36)}$.

\subsection{Analysis of mRNA expression}

Total RNA was extracted from $100 \mathrm{mg}$ of liver, using the TRIZOL Reagent(Invitrogen, Tokyo, Japan). A TaqMan® Universal PCR Master Mix (Applied Biosystems, Tokyo, Japan), Assays-on-DemandTM, Gene Expression Products (Mm00486279_m1 for acyl-coenzyme A[CoA]:cholesterol 
Effect of SPI on lipid metabolism in diet-induced liopodystrophy

Table 1 Ingredient composition of the experimental diets.

\begin{tabular}{|c|c|c|c|}
\hline & \multirow{2}{*}{ Normal } & \multicolumn{2}{|c|}{ Lipodystrophy model } \\
\hline & & Control & SPI \\
\hline & \multicolumn{3}{|c|}{$(\%)$} \\
\hline Casein & 20.0 & 20.0 & - \\
\hline Soy protein isolate & - & - & 20.5 \\
\hline$\alpha$-Cornstarch & 13.2 & 13.2 & 13.2 \\
\hline Sucrose & 10.0 & 10.0 & 10.0 \\
\hline Cellulose & 5.0 & 5.0 & 5.0 \\
\hline Mineral mixture (AIN-93G) & 3.5 & 3.5 & 3.5 \\
\hline Vitamin mixture (AIN-93) & 1.0 & 1.0 & 1.0 \\
\hline L-Cystein & 0.3 & 0.3 & 0.3 \\
\hline Choline bitartrate & 0.25 & 0.25 & 0.25 \\
\hline Corn oil & 4.0 & 4.0 & 4.0 \\
\hline High-linoleic safflower oil ${ }^{1}$ & 2.0 & - & - \\
\hline Conjugated linoleic acid ${ }^{2}$ & - & 2.0 & 2.0 \\
\hline tert-Butylhydroquinone & 0.0014 & 0.0014 & 0.0014 \\
\hline$\beta$-Cornstarch & 40.7486 & 40.7486 & 40.2486 \\
\hline
\end{tabular}

acyltransferase-1[ACAT1], Mm01304289_m1 for acetylCoA carboxylase-1[ACC1], Mm01204659_m1 for ACC2, Mm01204659_m1 for ACC2, Mm00484152_m1 for cholesterol 7-alpha hydroxylase[CYP7A1], Mm00662319_m1 for FAS, and Mm03928991_g1 for 18S RNA; Applied Biosystems, Tokyo, Japan) and a TaqMan ${ }^{\circledR}$ MGB Gene Expression Kit for 3-hydroxy-3-methyl-glutaryl-CoA (HMG-CoA) reductase (forward primer, 5'-AGTGATTGTGTCAGTATTATTGTGGAAG-3'; reverse primer, 5'-GGTACTGGCTGAAAAGTCACAAGAG-3'; and TaqMan® MGB probe, 5'-FAM-TTGCTGTTGTATGTAAAGT-MGB-3') were used for the quantitative real-time RT-PCR analysis of the ACAT1, ACC1, ACC2, CYP7A1, FAS, HMG-CoA reductase and 18S RNA expression in the liver. The amplification was performed using a real-time PCR system (ABI Prism 7000 Sequence Detection System; Applied Biosystems). The results are expressed as a relative value after normalization to the 18S RNA expression.

\subsection{Statistical analysis}

All values are expressed as the mean \pm standard error. Differences among three groups were analyzed by one-way ANOVA and all detected differences were further analyzed using a Tukey-Kramer post hoc test. The Wilcoxon-MannWhitney test was used to evaluate the differences in hepatic triglyceride levels between two groups since the data were not a good fit to normal distribution.

\section{Results}

3.1 Effects of dietary SPI on growth parameters in dietinduced lipodystrophy model mice

Table 2 summarizes liver and white adipose tissue weights of C57BL/6J mice after the 4 -wk feeding periods for the different diets. Although there was no significant difference in the final body weight (Normal, 18.5 $\pm 0.4 \mathrm{~g}$; Control, $19.2 \pm 0.4 \mathrm{~g}$; SPI, $18.3 \pm 0.4 \mathrm{~g}$ ) or total food intake (Normal, 70.5 \pm 0.6 g; Control, 70.4 \pm 1.2 g; SPI, 70.4 \pm 1.5 g) among the groups, the lipodystrophy-control diet significantly increased the liver weight of mice, as has been reported elsewhere ${ }^{19)}$. However, supplementing the lipodystrophy model diet with SPI alleviated, but not significantly, the hepatomegaly in the diet-induced lipodystrophy model mice. The weights of the abdominal WATs, such as the perirenal and epididymal tissues, were significantly decreased in the lipodystrophy model mice, and there was no significant effect of SPI feeding on the WAT weights in this model.

\subsection{Effects of dietary SPI on liver histology and hepatic lipid levels in diet-induced lipodystrophy model mice}

As shown in Fig. 1, macrovesicular hepatocytes were observed in the mice fed the lipodystrophy-control diet but were markedly reduced in the mice fed the lipodystrophySPI diet.

Figure 2 shows the hepatic triglyceride and cholesterol levels of C57BL/6J mice after the 4 -wk diet period. The 


\section{K. Nagao, A. Matsumoto and S. Kai et al.}

Table 2 Effect of experimental diets on liver and white adipose tissue weights.

\begin{tabular}{lccc}
\hline & \multirow{2}{*}{ Normal } & \multicolumn{2}{c}{ Lipodystrophy model } \\
\cline { 3 - 4 } & & Control & SPI \\
\hline Liver weight $(\mathrm{g} / 100 \mathrm{~g} \mathrm{BW})$ & $4.24 \pm 0.08^{\mathrm{a}}$ & $7.46 \pm 0.67^{\mathrm{b}}$ & $6.83 \pm 0.25^{\mathrm{b}}$ \\
WAT weight $(\mathrm{g} / 100 \mathrm{~g} \mathrm{BW})$ & & & \\
Total & $1.11 \pm 0.17^{\mathrm{a}}$ & $0.166 \pm 0.027^{\mathrm{b}}$ & $0.165 \pm 0.016^{\mathrm{b}}$ \\
$\quad$ Epididymal & $0.660 \pm 0.130^{\mathrm{a}}$ & $0.0705 \pm 0.0075^{\mathrm{b}}$ & $0.0884 \pm 0.0064^{\mathrm{b}}$ \\
$\quad$ Perirenal & $0.430 \pm 0.043^{\mathrm{a}}$ & $0.0952 \pm 0.0228^{\mathrm{b}}$ & $0.0770 \pm 0.0141^{\mathrm{b}}$ \\
\hline
\end{tabular}

Values are expressed as the mean \pm standard error of five mice.

${ }^{\mathrm{ab}}$ The different superscripted letters indicate significant differences at $p<0.05$.

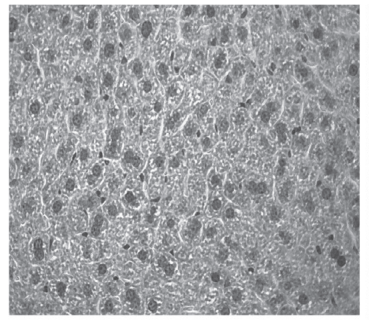

Normal

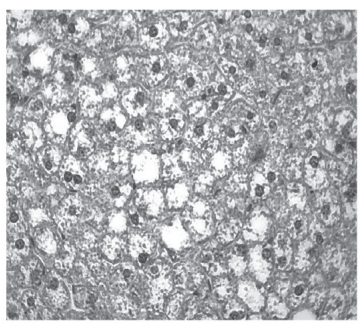

Control

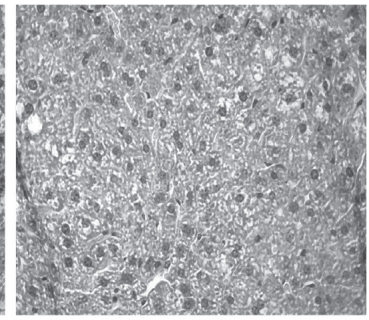

SPI

\section{Lipodystrophy}

Fig. 1 Effect of SPI on liver histology in diet-induced lipodystrophy model mice. Mice were fed diets containing 20\% casein and a mixture of $4 \%$ corn oil $+2 \% \operatorname{HL}-\mathrm{SAF}$ (normal), $20 \%$ casein and a mixture of $4 \%$ corn oil + $2 \%$ CLA (lipodystrophy-control), or 20.5\% SPI and a mixture of 4\% corn oil $+2 \%$ CLA (lipodystrophy-SPI) for 4 wk.

Hepatic Triglyceride ( $\mathrm{mg} /$ liver)

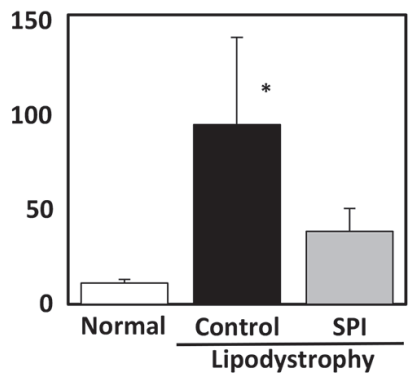

Fig. 2 Effect of SPI on the hepatic lipid levels in dietinduced lipodystrophy model mice. Mice were fed diets containing $20 \%$ casein and a mixture of $4 \%$ corn oil $+2 \%$ HL-SAF (normal), $20 \%$ casein and a mixture of $4 \%$ corn oil $+2 \%$ CLA (lipodystrophycontrol), or $20.5 \%$ SPI and a mixture of $4 \%$ corn oil + $2 \%$ CLA (lipodystrophy-SPI) for $4 \mathrm{wk}$. Values are expressed as the mean \pm standard error of five mice. The different letters indicate significant differences at $p<0.05$. The asterisk shows significant difference between normal group and lipodystrophy-control group at $p=0.016$ (by Wilcoxon-Mann-Whitney test) . hepatic triglyceride level in the mice fed the lipodystrophy model diet was 8.5-fold that in the mice fed a normal diet, and supplementing the lipodystrophy model diet with SPI attenuate, but not significantly, triglyceride accumulation (by 59\%) in the liver. In addition, hepatic cholesterol accumulation (2.8-fold) was induced by the lipodystrophy model diet. Supplementing the lipodystrophy model diet with SPI significantly decreased the hepatic level of cholesterol (by $40 \%$ ), especially the esterified form (by $57 \%$ ).

\subsection{Effects of dietary SPI on serum parameters in diet- induced lipodystrophy model mice}

Table 3 summarizes the serum parameters of C57BL/6J mice after the 4 -wk diet period. The serum triglyceride levels were significantly decreased by the lipodystrophy model diet, and this decrease was not changed by the SPI supplementation. However, the serum cholesterol levels were significantly increased by the lipodystrophy model diet, and this increase was not changed by the SPI supplementation. The serum glucose and insulin levels were slightly lowered in SPI group but were not significantly changed among groups. The serum levels of adipocytokines, such as adiponectin and leptin, were drastically decreased by the lipodystrophy model diet, as previously reported $^{19)}$, and SPI supplementation did not alter those levels. 
Table 3 Effect of experimental diets on serum parameters.

\begin{tabular}{lccc}
\hline & \multirow{2}{*}{ Normal } & \multicolumn{2}{c}{ Lipodystrophy model } \\
\cline { 3 - 4 } & & Control & SPI \\
\hline Triglyceride $(\mathrm{mg} / \mathrm{dl})$ & $32.6 \pm 2.3^{\mathrm{a}}$ & $23.7 \pm 2.4^{\mathrm{b}}$ & $21.1 \pm 3.2^{\mathrm{b}}$ \\
Cholesterol $(\mathrm{mg} / \mathrm{dl})$ & $85.2 \pm 2.5^{\mathrm{a}}$ & $138 \pm 8^{\mathrm{b}}$ & $135 \pm 13^{\mathrm{b}}$ \\
Glucose $(\mathrm{mg} / \mathrm{dl})$ & $215 \pm 8$ & $206 \pm 14$ & $187 \pm 8$ \\
Insulin $(\mathrm{ng} / \mathrm{ml})$ & $1.89 \pm 0.61$ & $1.96 \pm 0.77$ & $1.01 \pm 0.34$ \\
Leptin $(\mathrm{pg} / \mathrm{ml})$ & $137 \pm 39^{\mathrm{a}}$ & $33.8 \pm 14.0^{\mathrm{b}}$ & $30.0 \pm 12.9^{\mathrm{b}}$ \\
Adiponectin $(\mu \mathrm{g} / \mathrm{ml})$ & $27.3 \pm 2.5^{\mathrm{a}}$ & $3.01 \pm 0.12^{\mathrm{b}}$ & $3.31 \pm 0.21^{\mathrm{b}}$ \\
\hline
\end{tabular}

Values are expressed as the mean \pm standard error of five mice.

${ }^{\mathrm{ab}}$ The different superscripted letters indicate significant differences at $p<0.05$.

3.4 Effects of dietary SPI on the activities of hepatic enzymes related to lipid metabolism in diet-induced lipodystrophy model mice

Figure 3 shows the hepatic enzyme activities of C57BL/6J mice after the 4-wk diet period. The lipodystrophy model diet markedly increased the activity of hepatic lipogenic enzymes such as FAS, G6PDH and malic enzyme. However, SPI supplementation significantly decreased the activities of FAS and G6PDH compared with those for the lipodystrophy-control diet. Mitochondrial $\beta$-oxidation, whose rate-limiting enzyme is CPT, was significantly increased by the lipodystrophy model diet, and this increase was not changed by the SPI supplementation.

\subsection{Effects of dietary SPI on the expression of mRNAs} related to hepatic lipid metabolism in diet-induced lipodystrophy model mice

Table 4 summarizes the hepatic mRNA abundances of C57BL/6J mice after the 4-wk diet period. Consistent with enzyme activity, the mRNA levels of lipogenic genes, such as ACC1, ACC2 and FAS were increased (3.4-fold, 4.2-fold and 5.0-fold, respectively) by the lipodystrophy model diet, but the increase was attenuated (by 33\%, 29\% and 32\%, respectively) by SPI supplementation. The mRNA levels of HMG-CoA reductase and ACAT-1, which are related to hepatic cholesterol storage, were also increased by the lipodystrophy model diet during the onset of fatty liver, but SPI supplementation tended to attenuate this increase. In addition, the mRNA levels of CYP7A1, which is related to hepatic cholesterol catabolism, tended to decrease with the lipodystrophy model diet, but a significant increase (1.6-fold) was induced by SPI supplementation.

\section{Discussion}

In this study, marked disappearance of macrovesicular hepatocyte and $59 \%$ decrease tendency of hepatic triglyceride levels suggest that dietary SPI can alleviate lipodystrophy-induced hepatic steatosis in model mice. Previous
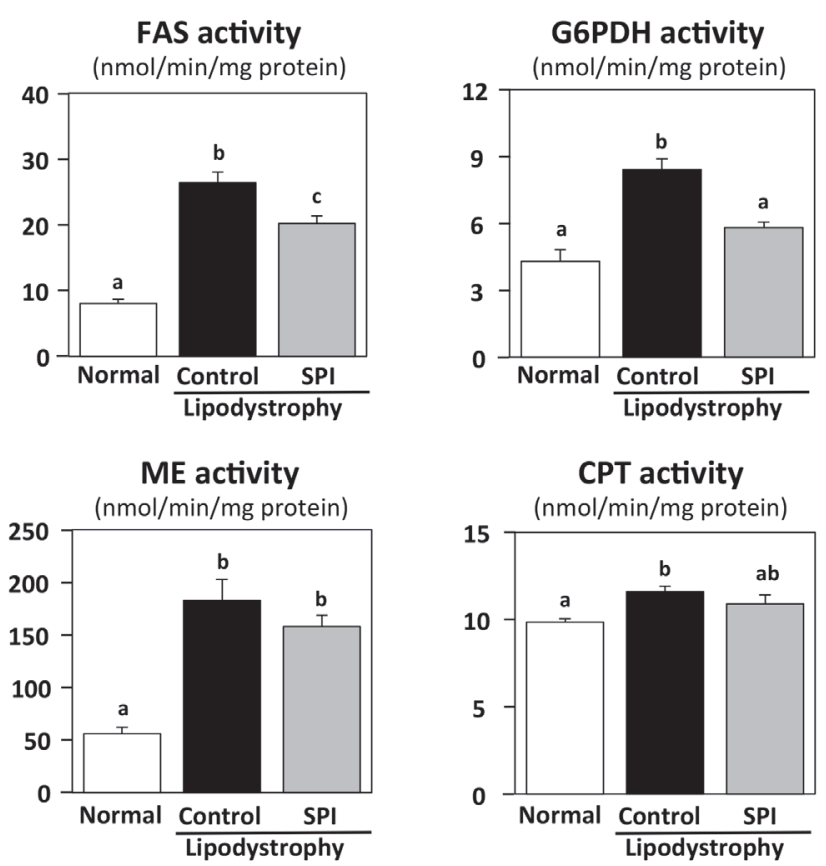

Fig. 3 Effect of SPI on hepatic enzyme activities in dietinduced lipodystrophy model mice. Mice were fed diets containing $20 \%$ casein and a mixture of $4 \%$ corn oil $+2 \%$ HL-SAF (normal), 20\% casein and a mixture of $4 \%$ corn oil $+2 \%$ CLA (lipodystrophycontrol), or $20.5 \%$ SPI and a mixture of $4 \%$ corn oil $+2 \%$ CLA (lipodystrophy-SPI) for 4 wk. Values are expressed as the mean \pm standard error for five mice. The different letters indicate significant differences at $p<0.05$.

reports demonstrated that enhanced lipogenesis is the principal mechanism of hepatic steatosis in the diet-induced lipodystrophy model mice ${ }^{19,34)}$. In the present study, suppression of the activities and mRNA expression of lipogenic enzymes (such as FAS, G6PDH, ACC1 and ACC2)resulted in lowered hepatic triglyceride content in mice fed the lipodystrophy-SPI diet(Fig. 3 and Table 4). The gene expression of ACC1, ACC2 and FAS is regulated by sterol- 
K. Nagao, A. Matsumoto and S. Kai et al.

Table 4 Effect of experimental diets on the expression of mRNAs related to lipid metabolism.

\begin{tabular}{|c|c|c|c|}
\hline & \multirow{2}{*}{ Normal } & \multicolumn{2}{|c|}{ Lipodystrophy model } \\
\hline & & Control & SPI \\
\hline & & & (arbitrary unit) \\
\hline $\mathrm{ACC} 1$ & $100 \pm 18^{\mathrm{a}}$ & $338 \pm 31^{\mathrm{b}}$ & $226 \pm 18^{\mathrm{c}}$ \\
\hline $\mathrm{ACC} 2$ & $100 \pm 17^{\mathrm{a}}$ & $417 \pm 58^{\mathrm{b}}$ & $296 \pm 60^{c}$ \\
\hline FAS & $100 \pm 22^{\mathrm{a}}$ & $495 \pm 37^{\mathrm{b}}$ & $332 \pm 39^{\mathrm{c}}$ \\
\hline HMG-CoA reductase & $100 \pm 14^{\mathrm{a}}$ & $280 \pm 40^{\mathrm{b}}$ & $225 \pm 12^{\mathrm{b}}$ \\
\hline ACAT1 & $100 \pm 21$ & $144 \pm 44$ & $105 \pm 18$ \\
\hline CYP7A1 & $100 \pm 18^{\mathrm{ab}}$ & $83.4 \pm 11.2^{\mathrm{a}}$ & $130 \pm 12^{\mathrm{b}}$ \\
\hline
\end{tabular}

Values are expressed as the mean \pm standard error of five mice.

${ }^{\text {abc }}$ The different superscripted letters indicate significant differences at $p<0.05$.

regulatory element binding protein-1 (SREBP-1), a lipogenic transcriptional factor. Previous studies have shown that SPI has a suppressive effect on SREBP-1 mRNA expression $^{37,38)}$, which suggests that SPI can decrease fatty acid synthesis through transcriptional suppression of SREBP-1 signaling. Therefore, the alleviation of hepatic steatosis by SPI supplementation might be attributable to the transcriptional suppression of fatty acid synthesis in the diet-induced lipodystrophy model mice. On the other hand, the activity of CPT, a rate-limiting enzyme of fatty acid $\beta$-oxidation, was not changed by supplementing the lipodystrophy model diet with SPI. Although SPI has been reported to have the ability to enhance fatty-acid $\beta$-oxidation through the activation of peroxisome proliferator-activated receptor- $\alpha$, a lipolytic transcriptional factor ${ }^{38}$, the results suggest that effect of SPI on lipolysis does not contribute to the attenuation of hepatic steatosis in the diet-induced lipodystrophy model mice.

After a 4-wk feeding period, hepatic cholesterol accumulation was induced by the lipodystrophy model diet, and this accumulation was markedly attenuated by SPI supplementation. HMG-CoA reductase, a rate-limiting enzyme of cholesterol synthesis, and ACAT-1, a rate-limiting enzyme of cholesterol esterification, are related to hepatic cholesterol storage. The mRNA levels of these enzymes were also increased by the lipodystrophy model diet during the onset of hepatic steatosis, but SPI supplementation tended to attenuate this increase (Table 4). In particular, marked reduction of the hepatic content of esterified cholesterol might be attributable to the suppressive effect of SPI on ACAT-1. Additionally, the mRNA levels of CYP7A1, a ratelimiting enzyme of cholesterol catabolism, were significantly increased by the lipodystrophy-SPI diet compared with those observed in mice fed the lipodystrophy-control diet. Because increased expression of CYP7A1 mRNA in response to SPI consumption has been reported by others ${ }^{39)}$, enhanced cholesterol catabolism by SPI might contribute to the suppression of cholesterol accumulation in the liver of diet-induced lipodystrophy model mice.

Hepatic lipid homeostasis is also influenced by lipoprotein synthesis, secretion to the circulation and reuptake into the liver. However, serum levels of triglyceride and cholesterol were not changed by the SPI supplementation in this study (Table 3). Therefore, SPI exerted the suppressive effect on hepatic lipid accumulation in this model mice may through the effects on synthesis and catabolism of lipids in the liver, but not though the alterations in lipoprotein flow.

As shown in Table 3, the serum levels of adiponectin and leptin were drastically decreased in the diet-induced lipodystrophy model mice, as previously reported ${ }^{19,25)}$. Adiponectin and leptin are both abundantly secreted from adipose tissue and have several physiological functions, including the regulation of insulin sensitivity in humans and animals. Therefore, it has been reported that the deficiency of adipocytokine secretion induced by a paucity of adipose tissue would cause lipodystrophy, which is characterized by severe insulin resistance, and leads to hyperinsulinemia and hepatic steatosis ${ }^{9,10)}$. Additionally, SPI has been reported to increase serum adiponectin levels due to increased mRNA expression ${ }^{40)}$. Thus we hypothesized that the SPI-mediated alleviation of hepatic steatosis observed in this study was accompanied by a parallel increase in adipocytokine levels. However, SPI supplementation of the lipodystrophy model diet did not affect the adipocytokine levels compared with those observed in the lipodystrophycontrol diet. Although SPI supplementation tended to decrease the serum insulin level, hyperinsulinemia and hyperglycemia were not induced by the lipodystrophy model diet in this study (Table 3). These results suggest that in this study, the hepatic steatosis induced by the lipodystrophy model diet was attenuated by SPI supplementation through suppression of hepatic lipogenesis rather than through regulation of adipocytokine production and insulin 


\section{Effect of SPI on lipid metabolism in diet-induced liopodystrophy}

sensitivity in mice.

In conclusion, these results suggest that SPI can attenuate hepatic lipid accumulation by directly reducing hepatic fatty acid synthesis and enhancing cholesterol catabolism without affecting adipocytokine production in the diet-induced lipodystrophy model mice. Multiple beneficial effects of SPI have been attributed to the bioactivities of $\beta$-conglycinin, one of major protein components in $\mathrm{SPI}^{29,41)}$. Threfore, in vivo study using other lipodystrophy mice models and clinical trials that evaluate the efficacy of dietary SPI(or $\beta$-conglycinin) treatment on hepatic steatosis in patients with several types of lipodystrophy syndrome, including HALS, would be of great interest for future study.

\section{Competing interests}

The authors declare that they have no competing interests.

\section{Authors' contributions}

$\mathrm{KN}$ made substantial contributions to the conception and design of the study, performing the experiment, assembling, analyzing and interpreting the data and drafting the manuscript. AM, SK and TK participated in the experimental work and in collecting, assembling, analyzing the data. TY contributed to planning the experiment and discussing the results. All authors read and approved the final manuscript.

\section{Acknowledgments}

This work was supported by a research grant from the Japanese Ministry of Education, Culture, Sports, Science and Technology (JSPS KAKENHI Grant Number 23580173). We thank the Nisshin OilliO Group Ltd. (Yokohama, Japan) and Fuji Oil Co. (Osaka, Japan)for providing sample oils and soy protein isolate, respectively.

\section{References}

1) Matsuzawa, Y.; Funahashi, T.; Nakamura, T. Molecular mechanism of metabolic syndrome X: Contribution of adipocytokines and adipocyte-derived bioactive substances. Ann. N.Y. Acad. Sci. 892, 146-154(1999).

2) Hotamisligil, G.S.; Shargill, N.S.; Spiegelman, B.M. Adipose expression of tumor necrosis factor-alpha: direct role in obesity-linked insulin resistance. Science 259, 87-91 (1993).
3) Sartipy, P.; Loskutoff, D.J. Monocyte chemoattractant protein 1 in obesity and insulin resistance. Proc. Natl. Acad. Sci. USA 100, 7265-7270 (2003).

4) Wang, B.; Jenkins, J.R.; Trayhurn, P. Expression and secretion of inflammation-related adipokines by human adipocytes differentiated in culture: integrated response to TNF-alpha. Am. J. Physiol. Endocrinol. Metab. 288, E731-E740(2005).

5) Kanda, H.; Tateya, S.; Tamori, Y.; Kotani, K.; Hiasa, K.; Kitazawa, R.; Kitazawa, S.; Miyachi, H.; Maeda, S.; Egashira, K.; Kasuga, M. MCP-1 contributes to macrophage infiltration into adipose tissue, insulin resistance, and hepatic steatosis in obesity. J. Clin. Invest. 116, 1494-1505 (2006).

6) Ahima, R.S.; Flier, J.S. Leptin. Annu. Rev. Physiol. 62, 413-437(2002).

7) Arita, Y.; Kihara, S.; Ouchi, N.; Takahashi, M.; Maeda, K.; Miyagawa, J,; Hotta, K.; Shimomura, I.; Nakamura, T.; Miyaoka, K.; Kuriyama, H.; Nishida, M.; Yamashita, S.; Okubo, K.; Matsubara, K.; Muraguchi, M.; Ohmoto, Y.; Funahashi, T.; Matsuzawa, Y. Paradoxical decrease of an adipose-specific protein, adiponectin, in obesity. Biochem. Biophys. Res. Commun. 257, 79-83 (1999).

8) Hotta, K.; Funahashi, T.; Bodkin, N.L.; Ortmeyer, H.K.; Arita, Y.; Hansen, B.C.; Matsuzawa, Y. Circulating concentrations of the adipocyte protein adiponectin are decreased in parallel with reduced insulin sensitivity during the progression to type 2 diabetes in rhesus monkeys. Diabetes 50, 1126-1133(2001).

9) Simha, V.; Garg, A. Lipodystrophy: lessons in lipid and energy metabolism. Curr. Opin. Lipidol. 17, 162-169 (2006).

10) Fiorenza, C.G.; Chou, S.H.; Mantzoros, C.S. Lipodystrophy: pathophysiology and advances in treatment. Nat. Rev. Endocrinol. 7, 137-150 (2011).

11) Shimomura, I.; Hammer, R.E.; Richardson, J.A.; Ikemoto, S.; Bashmakov, Y.; Goldstein, J.L.; Brown, M.S. Insulin resistance and diabetes mellitus in transgenic mice expressing nuclear SREBP-1c in adipose tissue: model for congenital generalized lipodystrophy. Genes Dev. 12, 3182-3194(1998).

12) Horton, J.D.; Shimomural, I.; Ikemoto, S.; Bashmakov, Y.; Hammer, R.E. Overexpression of sterol regulatory element-binding protein-1a in mouse adipose tissue produces adipocyte hypertrophy, increased fatty acid secretion, and fatty liver. J. Biol. Chem. 278, 3665236660 (2003).

13) Moitra, J.; Mason, M.M.; Olive, M.; Krylov, D.; Gavrilova, O. Marcus-Samuels, B.; Feigenbaum, L.; Lee, E.; Aoyama, T.; Eckhaus, M.; Reitman, M.L.; Vinson, C. Life without white fat: a transgenic mouse. Genes Dev. 12, 3168-3181 (1998).

14) Reitman, M.L.; Gavrilova, O. A-ZIP/F-1 mice lacking 


\section{K. Nagao, A. Matsumoto and S. Kai et al.}

white fat: a model for understanding lipoatrophic diabetes. Int. J. Obes. Relat. Metab. Disord. 24, S11-14 (2000).

15) Ohashi, A.; Matsushita, Y.; Shibata, H.; Kimura, K.; Miyashita, K.; Saito, M. Conjugated linoleic acid deteriorates insulin resistance in obese/diabetic mice in association with decreased production of adiponectin and leptin. J. Nutr. Sci. Vitaminol. 50, 416-421 (2004).

16) Poirier, H.; Rouault, C.; Clement, L.; Niot, I.; Monnot, M.C.; Guerre-Millo, M.; Besnard, P. Hyperinsulinaemia triggered by dietary conjugated linoleic acid is associated with a decrease in leptin and adiponectin plasma levels and pancreatic beta cell hyperplasia in the mouse. Diabetologia 48, 1059-1065 (2005).

17) Tsuboyama-Kasaoka, N.; Miyazaki, H.; Kasaoka, S.; Ezaki, O. Increasing the amount of fat in a conjugated linoleic acid-supplemented diet reduces lipodystrophy in mice. J. Nutr. 133, 1793-1799 (2003).

18) Wang, Y.M.; Nagao, K.; Ujino, Y.; Sakata, K.; Higa, K.; Inoue, N.; Yanagita, T. Short-term feeding of conjugated linoleic acid does not induce hepatic steatosis in C57BL/6J mice. J. Nutr. Sci. Vitaminol. 51, 440-444 (2005).

19) Nagao, K.; Inoue, N.; Ujino, Y.; Higa, K.; Shirouchi, B.; Wang, Y.M.; Yanagita, T. Effect of leptin infusion on insulin sensitivity and lipid metabolism in diet-induced lipodystrophy model mice. Lipids Health Dis. 7, 8 (2008) .

20) Shimomura, I.; Hammer, R.E.; Ikemoto, S.; Brown, M.S.; Goldstein, J.L. Leptin reverses insulin resistance and diabetes mellitus in mice with congenital lipodystrophy. Nature 401, 73-76 (1999).

21) Rodríguez, A.J.; Neeman, T.; Giles, A.G.; Mastronardi, C.A.; Paz Filho, G. Leptin replacement therapy for the treatment of non-HAART associated lipodystrophy syndromes: a meta-analysis into the effects of leptin on metabolic and hepatic endpoints. Arq. Bras. Endocrinol. Metabol. 58, 783-797 (2014).

22) Tsoukas, M.A.; Farr, O.M.; Mantzoros, C.S. Leptin in congenital and HIV-associated lipodystrophy. Metabolism 64, 47-59 (2015).

23) Wohl, D.A.; Tien, H.C.; Busby, M.; Cunningham, C.; Macintosh, B.; Napravnik, S.; Danan, E.; Donovan, K.; Hossenipour, M.; Simpson, R.J.Jr. Randomized study of the safety and efficacy of fish oil (omega-3 fatty acid) supplementation with dietary and exercise counseling for the treatment of antiretroviral therapy-associated hypertriglyceridemia. Clin. Infect. Dis. 41, 1498-1504 (2005).

24) Woods, M.N.; Wanke, C.A.; Ling, P.R.; Hendricks, K.M.; Tang, A.M.; Knox, T.A.; Andersson, C.E.; Dong, K.R.; Skinner, S.C.; Bistrian, B.R. Effect of a dietary intervention and n-3 fatty acid supplementation on measures of serum lipid and insulin sensitivity in persons with HIV. Am. J. Clin. Nutr. 90, 1566-1578(2009).

25) Yanagita, T.; Wang, Y.M.; Nagao, K.; Ujino, Y.; Inoue, N. Conjugated linoleic acid-induced fatty liver can be attenuated by combination with docosahexaenoic acid in C57BL/6N mice. J. Agric. Food Chem. 53, 96299633 (2005).

26) Tovar, A.R.; Torres, N. The role of dietary protein on lipotoxicity. Biochim. Biophys. Acta 1801, 367-371 (2010).

27) Sirtori, C.R.; Galli, C.; Anderson, J.W.; Arnoldi, A. Nutritional and nutraceutical approaches to dyslipidemia and atherosclerosis prevention: Focus on dietary proteins. Atherosclerosis 203, 8-17 (2009).

28) Sakono, M.; Yoshida, K.; Yahiro, M. Combined effects of dietary protein and fat on lipid metabolism in rats. $J$. Nutr. Sci. Vitaminol. 39, 335-343(1993).

29) Inoue, N.; Nagao, K.; Sakata, K.; Yamano, N.; Gunawardena, E.R.P.; Han, S.Y.; Matsui, T.; Nakamori, T.; Furuta, H.; Takamatsu, K.; Yanagita, T. Screening of soy protein-derived hypotriglyceridemic di-peptides in $v i$ tro and in vivo. Lipids Health Dis. 10, 85 (2011).

30) Reeves, P.G.; Nielsen, F.H.; Fahey, G.C.Jr. AIN-93 purified diets for laboratory rodents: final report of the American Institute of Nutrition ad hoc writing committee on the reformulation of the AIN-76A rodent diet. J. Nutr. 123, 1939-1951 (1993).

31) Folch, J.; Lee, M.; Sloane-Stanley, G.H. A simple method for the isolation and purification of total lipids from animal tissues. J. Biol. Chem. 226, 497-509 (1957).

32) Fletcher, M.J. A colorimetric method for estimation of serum triglycerides. Clin. Chem. Acta 22, 393-397 (1968).

33) Sperry, W.M.; Webb, M. A revision of the ShoenheimerSperry method for cholesterol determination. J. Biol. Chem. 187, 97-106 (1950).

34) Nagao, K.; Yamano, N.; Shirouchi, B.; Inoue, N.; Murakami, S.; Sasaki, T.; Yanagita, T. Effects of citrus auraptene (7-geranyloxycoumarin) on hepatic lipid metabolism in vitro and in vivo. J. Agric. Food Chem. 58, 9028-9032 (2010).

35) Lowry, O.H.; Rosebrough, N.J.; Farr, A.L. Randall RJ. Protein measurement with the folin phenol reagent. $J$. Biol. Chem. 193, 265-275(1951).

36) Gotoh, N.: Nagao, K.; Onoda, S.; Shirouchi, B.; Furuya, K.; Nagai, T.; Mizobe, H.; Ichioka, K.; Watanabe, H.; Yanagita, T.; Wada, S. Effect of three different highly purified n-3 series highly unsaturated fatty acids on lipid metabolism in C57BL/KsJ-db/db mice. J. Agric. Food Chem. 57, 11047-11054(2009).

37) Oliveira, L.P.; de Jesús, R.P.; Freire, T.O.; Oliveira, C.P.; Castro Lyra, A.; Lyra, L.G.. Possible molecular mechanisms soy-mediated in preventing and treating nonalcoholic fatty liver disease. Nutr. Hosp. 27, 991-998 (2012). 
38) Ronis, M.J.; Chen, Y.; Badeaux, J.; Badger, T.M. Dietary soy protein isolate attenuates metabolic syndrome in rats via effects on PPAR, LXR, and SREBP signaling. $J$. Nutr. 139, 1431-1438(2009).

39) Ikeda, I.; Kudo, M.; Hamada, T.; Nagao, K.; Oshiro, Y.; Kato, M.; Sugawara, T.; Yamahira, T.; Ito, H.; Tamaru, S.; Sato, M.; Imaizumi, K.; Nagaoka, S.; Yanagita, T. Dietary soy protein isolate and its undigested high molecular fraction upregulate hepatic ATP-binding cassette transporter G5 and ATP-binding cassette transporter G8 mRNA and increase biliary secretion of cholesterol in rats. J. Nutr. Sci. Vitaminol. 55, 252256 (2009).
40) Nagasawa, A.; Fukui, K.; Kojima, M.; Kishida, K.; Maeda, N.; Nagaretani, H.; Hibuse, T.; Nishizawa, H.; Kihara, S.; Waki, M.; Takamatsu, K.; Funahashi, T.; Matsuzawa, Y. Divergent effects of soy protein diet on the expression of adipocytokines. Biochem. Biophys. Res. Commun. 311, 909-914(2003).

41) Wanezaki, S.; Tachibana, N.; Nagata, M.; Saito, S.; Nagao, K.; Yanagita, T.; Kohno, M. Soy $\beta$-conglycinin improves obesity-induced metabolic abnormalities in a rat model of nonalcoholic fatty liver disease. Obes. Res. Clin. Pract. 9, 168-174(2015). 